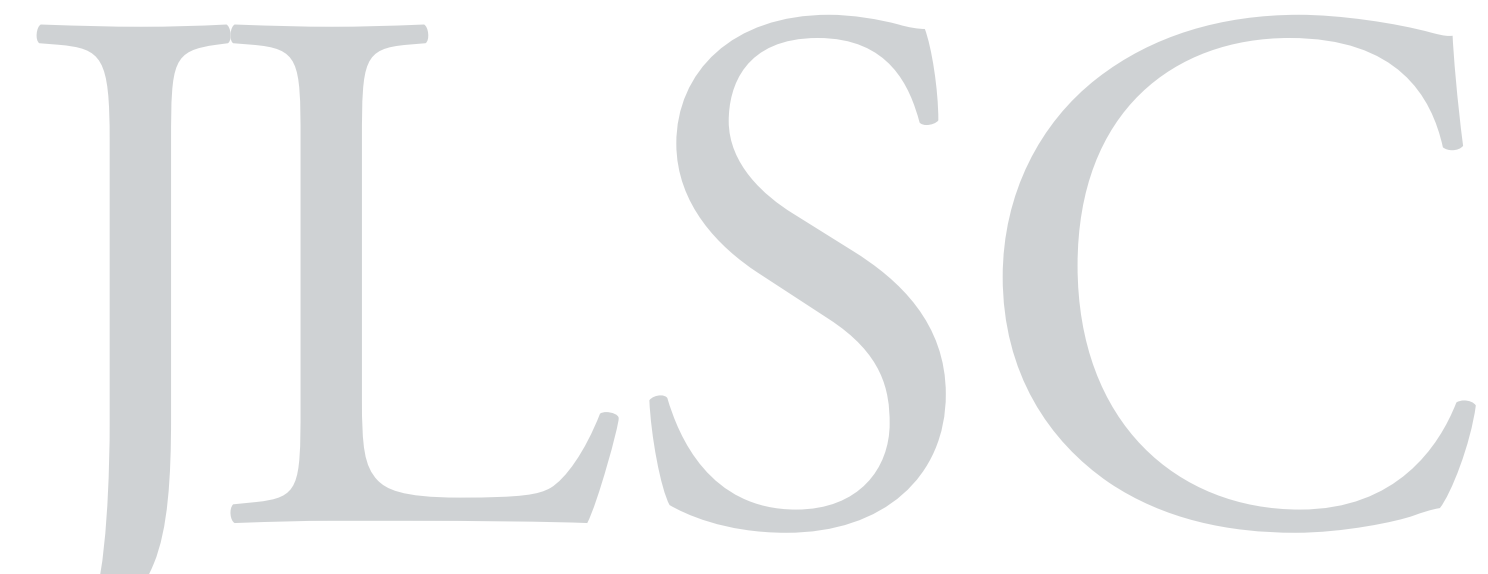

Volume 9, General Issue (2021)

\title{
Manuscript Accepted!: Collaborating on a Scholarly Publishing Symposium for Graduate Students and Early Career Academic Faculty
}

Teresa Auch Schultz, Rosalind Bucy, Amy Hunsaker, Amy Shannon, Chrissy Klenke, Mitch Winterman, \& Iñaki Arrieta Baro

Schultz, T.A., Bucy, R., Hunsaker, A., Shannon, A., Klenke, C., Winterman, M., \& Arrieta Baro, I. (2021). Manuscript Accepted!: Collaborating on a Scholarly Publishing Symposium for Graduate Students and Early Career Academic Faculty. Journal of Librarianship and Scholarly Communication, 9(General Issue), eP2385. https://doi.org/10.7710/2162-3309.2385

This article underwent fully-anonymous peer review in accordance with JLSC's peer review policy. 


\title{
Manuscript Accepted!: Collaborating on a Scholarly Publishing Symposium for Graduate Students and Early Career Academic Faculty
}

\author{
Teresa Auch Schultz \\ Social Sciences Librarian, University of Nevada, Reno \\ Rosalind Bucy \\ Humanities Librarian, University of Nevada, Reno \\ Amy Hunsaker \\ Research Librarian for Music and Performing Arts, University of Virginia \\ Amy Shannon \\ Life \& Environmental Sciences Librarian, University of Nevada, Reno \\ Chrissy Klenke \\ Earth Sciences, GIS, and Maps Librarian, University of Nevada, Reno \\ Mitch Winterman \\ Business and Economics Librarian, University of Nevada, Reno \\ Iñaki Arrieta Baro \\ Basque Librarian, University of Nevada, Reno
}

INTRODUCTION As academic libraries expand their scholarly communication support, they also need to find ways to help educate graduate students about this area as well as market themselves. DESCRIPTION OF PROGRAM The University of Nevada, Reno Libraries created a one-day symposium, called Manuscript Accepted!, aimed at graduate students and early career faculty that would use faculty and library expertise to lead panels and workshops. This article discusses planning for the event, including collaborating with other on-campus groups, working with publishers for financial support, and planning a program that would meet a variety of needs. Assessment of the first two symposiums, held in 2019 and 2020, shows that attendees valued the event while also highlighting the need for more targeted support for specific areas, such as the humanities. NEXT STEPS The Libraries plans to continue Manuscript Accepted! as a one-day symposium, although it will also look to ways to expand attendance. Finally, the Libraries is investigating ways to create smaller events that could be tied into the Manuscript Acceptance! brand but that help meet other needs of our attendees.

Received: 05/29/2020 Accepted: $01 / 22 / 2021$

Correspondence: Teresa Auch Schultz, 1664 N. Virginia Street, Reno 89557 MS 0322, teresas@unr.edu 


\section{INTRODUCTION}

University libraries are an essential component of academic research and scholarly publishing, having long offered services in support of literature reviews and evaluating journals to more recent areas such as open access (OA) publishing (Bruxvoort \& Fruin, 2014). However, libraries that offer instruction sessions to graduate students focused on scholarly communication issues appear to still be in the minority, and graduate programs themselves often do not address these needs either (Baruzzi \& Calcagno, 2015). With a growing graduate student population, the University of Nevada, Reno (UNR) Libraries wanted to create an effective and meaningful plan to support graduate students and faculty who might not have experience or understanding of the scholarly publishing world. As part of this work, the Libraries decided to offer a one-day, in-person symposium called Manuscript Accepted!. This would include speakers, panels, and workshops on various topics surrounding the publishing process.

UNR is a public, land grant institution. There are 72 undergraduate degrees/programs, 64 graduate degrees/programs, and $44 \mathrm{PhD}$ programs. In Fall 2018, the university had 17,513 undergraduate students, 3,233 graduate students, and 300 medical students (University of Nevada, Reno Office of Institutional Analysis, n.d.). UNR was designated as a Carnegie R1 University in December 2018. This designation is reserved for institutions with "very high research activity" (Carnegie Classification of Institutions of Higher Education, n.d.a). Criteria for R1 status places a large emphasis on the number of graduate degrees awarded from an institution (Carnegie Classification of Institutions of Higher Education, n.d.b)

In the interest of better supporting the university's growing numbers of graduate students, liaison librarians, split into subject clusters (STEM, Social Sciences, and Humanities), began to collaborate on ideas and strategies to accomplish this goal. The Social Science cluster sent a survey out to all graduate students in their departments in 2017. This survey aimed to obtain information about what graduate students wanted to learn, and the results indicated they needed more information about the publishing process, including communicating with editors, selecting publications, improving their writing, and learning about publishing success.

With these results in hand, the Social Sciences cluster started to explore the idea of holding an event focused on the scholarly publishing process designed for graduate students and eventually early career faculty interested in research and writing as a new endeavor or in need of additional training. From those discussions, the Libraries formed a committee that included two liaison librarians from each cluster to review, plan, and execute a publishingrelated event scheduled for Spring 2019. We had two main goals: help graduate students 
and early career faculty navigate scholarly publishing and promote the Libraries as a place that can help with this.

After reviewing what other academic libraries had offered in this area (McClellan, Detmering, Martinez, \& Johnson, 2017; Nova Southeastern University Libraries, 2017; University of Nevada, Las Vegas Libraries, n.d.), the committee decided on a single-day format that would feature both experts from within UNR as well as representatives from academic journal and book publishers. This article will discuss the details of planning and executing the event as well as the challenges, takeaways, and future considerations for improvements.

\section{LITERATURE REVIEW}

\section{Graduate Student and Early Career Faculty Needs}

The literature suggests that there is an increasing expectation that graduate students should publish before they leave their programs, while early career academic faculty experience a great amount of pressure to publish in addition to their primary teaching duties (Baruzzi \& Calcagno, 2015; Knievel, 2008). Although these early career scholars understand the importance of publishing their research, campus units tend not to offer basic training and support in this area. A variety of surveys have shown that institutions in general do not effectively meet the needs of graduate students and early career academic faculty who wish to learn about the publishing process (Fong, 2019; Fong et al., 2016; Hoffman, Antwi-Nsiah, Feng, \& Stanley, 2008). Indeed, Buehler and Zald note that, “...initial forays into the world of publishing occur primarily outside the classroom and curricular structures" (2013, p. 228).

Additionally, graduate students and early career academic faculty report high anxiety about scholarly publishing (Belcher, 2009). According to a 2005 survey of more than 40,000 U.S. faculty cited by Belcher, "...only $25 \%$ of faculty surveyed said they spend more than 8 hours a week writing, and only $28 \%$ had produced more than two publications in the past two years. That is, only a quarter of faculty are doing what everyone imagines professors do easily - write regularly" (2009, p. 185). In addition, Belcher outlined the anxiety shared by academics that keeps them from completing writing projects. Particularly, graduate students outside of the sciences received little training on how to write for publication, including how to select a journal or submit their work to editors. Early workshops on scholarly writing concepts saw hundreds of would-be students on a waiting list for 20 spaces. At these workshops, Belcher (2009) advised students and junior faculty how to revise their existing work to make it journal-ready. 
Yet, long-time faculty have different perceptions of what skills graduate students and early career academic faculty need. A 2013 study of graduate program directors and graduate students at Rutgers University in Newark found that graduate program directors did not prioritize teaching students about publishing despite the growing trend of early career publishing (Fong, Wang, White. \& Tipton, 2016). In fact, “...student concerns about publishing were not reflected in the directors' responses," indicating that a gap may exist between the publishing needs of graduate students and institutional support (Fong, Wang, White, \& Tipton, 2016, p. 571). Baruzzi and Calcagno (2015) refer to this "instruction gap" as a barrier to success in graduate school and academic careers.

\section{Library Support}

The Association of College and Research Libraries (ACRL) has been aware of the need for instruction in this area. The Information Literacy Competency Standards for Higher Education support the need to facilitate "self-directed investigations as individuals move into internships, first professional positions, and increasing responsibilities in all arenas of life" (Association of College \& Research Libraries, 2000, p. 6). The ACRL Framework for Information Literacy for Higher Education notes that, "Librarians have a greater responsibility in identifying core ideas within their own knowledge domain that can extend learning for students, in creating a new cohesive curriculum for information literacy, and in collaborating more extensively with faculty" (Association of College \& Research Libraries, 2016, p. 7). The Framework encourages librarians to assist graduate students and early career academic faculty in their scholarly publishing needs. It is also a priority laid out by the Association of Research Libraries (ARL) in the report, New Roles for New Times: Research Library Services for Graduate Students (Covert-Vail \& Collard, 2012). McClellen, Detmering, Martinez, \& Johnson refer to recommendations from the ARL report that librarians collaborate with academic units to better "create unique professional support communities" (2017, p. 547). Barbara Blummer (2009) reviewed the development of library instruction to graduate students over the decades and documented a post-2000 trend of increasing support for graduate student publishing efforts and post-grad academic career goals. Despite this increasing trend, as of 2015, a study of PhD-granting institution libraries found less than $1 \%$ of library instruction efforts to graduate students included scholarly communication topics, and only $18 \%$ of the libraries offered scholarly communication workshops at all (Baruzzi \& Calcagno, 2015).

Scholarly publication classes and workshops offered by libraries at academic institutions have drawn high responses (Baruzzi \& Calcagno, 2015; Fong, Wang, White, \& Tipton, 2016; Knievel, 2008; McClellan, Detmering, Martinez, \& Johnson, 2017). For example, the University of Colorado Boulder Libraries created the "Publish not Perish" set of online 
scholarly publishing tutorials. Within the first four weeks of their availability, they attained 1,439 viewers, including large numbers of graduate students, indicating a strong need not met elsewhere on campus (Knievel, 2008). The University of Louisville offered the Publishing Academy in 2017 to support the publishing needs of graduate students (McClellan, Detmering, Martinez, \& Johnson, 2017). Students could earn a certificate if they voluntarily attended four of the five classes. Although the Academy was primarily promoted via word of mouth, 23 graduate students attended the first class and the overall response was positive. Libraries have found partners in the effort to provide workshops and other scholarly publishing training. Fong (2019) refers to several instances of collaboration between libraries and academic units to produce courses, workshop series, online classes, publication events, training days, and tutorials. A librarian-led partnership at Rutgers University in Newark produced a set of 17 "Boot Camps for Graduate Student Success" in 2017-18 (Fong, 2019). Other examples exist as well. The University of Nevada, Las Vegas provided a weeklong series of workshops in 2017, in which speakers from a variety of campus units such as the writing center, Office of Sponsored Projects, and the Cannon Survey Center taught classes aimed at graduate students and early career academic faculty (University of Nevada, Las Vegas Libraries, n.d.). The University of Pennsylvania offers "Academic and Intellectual Programs" that target graduate students and provide a variety of workshops and events in partnership with campus units (Grad Center at Penn, n.d.). The Georgia Institute of Technology Library partnered with the Graduate Student Government Association to produce Graduate Library User Education (GLUE) classes that focused on teaching graduate students scholarly publishing skills (Critz et al., 2012). In addition, many scholarly publication events include the sponsorship of publishers, who are often willing to offer financial support in exchange for hosting workshops or social events. Nova Southeastern University in Florida holds annual "Power Publishing Day," in which invited academic publishers provide workshops such as how to submit successful manuscripts or interpret journal rankings (Nova Southeastern University Libraries, 2017).

\section{DESCRIPTION OF PROGRAM}

\section{Collaboration}

An early goal for Manuscript Accepted! was to find other on-campus partners the Libraries could collaborate with. From prior experience, we knew that events sponsored and planned only by the Libraries often garnered little interest and attendance from students. We also assumed that including other groups that target supporting graduate students and academic publishing in planning and marketing the event would help spread the reach of our marketing, which in turn would help increase attendance. 
We reached out to our Graduate School and Graduate Student Association (GSA) as potential collaborators. Along with their obvious interest in and connection to our main target audience of graduate students, the Libraries had previously successfully worked with these organizations and knew they could be relied on to take part in the work of planning and marketing this event. Another benefit of partnering with these groups included their access to email lists that reach a large number of faculty and graduate students on campus. We recognized early on that one area of struggle was the Libraries' lack of access to these types of resources, which would make marketing harder. A final benefit of working with the GSA is that they are not tied to using only the university's caterer for events, which allowed us to consider other vendors and helped keep costs down.

We also later identified the Early Career Academic Faculty Committee (ECAF), a committee of the UNR Faculty Senate, as another partner. There were obvious connections between their goal of supporting early career faculty and the goals of Manuscript Accepted!, as we saw early career faculty as another potential audience for the event. It also helped that a member of the Manuscript Accepted! planning committee chaired the ECAF committee at the time. The two groups agreed that the ECAF committee would oversee a panel populated by early career authors who could give advice that more experienced authors might have forgotten about or were not aware of because of how publishing trends have changed. Ultimately, the core planning committee included the six library representatives - two each representing STEM, social sciences, and arts and humanities liaisons - and two representatives from the GSA, including a student representative. The committee began meeting in April 2018 on a monthly basis.

\section{Sponsorship}

Based on what we had learned from other similar events and our own desire to provide a free event with food to help entice attendees, our first goal was to settle on levels of sponsorship opportunities and to then invite various publishers to sponsor this event. We based our sponsorship levels on providing a light breakfast, a full lunch, and an hour-long social reception with beer and wine after the event for an assumed attendance of 100 people, which came to an estimated budget of $\$ 2,100$ (this did not include money to rent space as that was not required by our university). We created three sponsorship levels of $\$ 500, \$ 750$, and $\$ 1,000$, with the goal of attracting three to four sponsors. Each level included adding the sponsor's logo to our marketing and posters, an acknowledgment during the event, and the ability to host a vendor table at the event where the publisher's representative could network with attendees. The $\$ 750$ level also included sponsorship of either the breakfast or lunch, and the $\$ 1,000$ level included sponsorship of the social hour. We ultimately had four publishers select the $\$ 500$ level, and one select the $\$ 750$ level. 
Deciding on what to include in the sponsorship levels exposed some possible ethical issues. We knew that other events had promised speaking slots to publishers as part of their sponsorship but that these slots often focused on marketing their products as opposed to looking at the broader aspect of a particular topic in scholarly publishing. While we were not against having publisher representatives speak at the event, we did not want that tied to their funding so that we could better direct the topics. Therefore, we opted to hold off on inviting any publishers to speak until after sponsorship was confirmed, and we did not limit speaking invitations to sponsors. This included book publishers, who we had not asked to sponsor the event over concerns about their financial ability to do so. However, we knew we still wanted book publisher representatives as panelists.

We were also interested in including OA publishers, but this proved harder to accomplish. We had established contacts with traditional publishers, which gave us a clear path to an initial contact. However, we found that trying to find an initial point-of-contact person at OA publishers was much more difficult, and we never heard back from those we contacted. This could partially be due to our university's lack of formalized participation in OA publishing, such as through agreements with open access publishers or even an OA publishing fund.

\section{Marketing}

Through our partnership with the GSA, we advertised Manuscript Accepted! to all graduate students in an email from the Dean of the Graduate School, which also went to graduate directors and graduate faculty. A library newsletter to all faculty announced the event early in the spring semester. Although we welcomed attendees from other institutions who discovered the event through word of mouth, we did not advertise outside our institution. In addition to email marketing, we worked closely with the Marketing Specialist for the Libraries to devise a marketing strategy, including the development of an event logo. Initial registration for the event was so successful following the email message from the dean of the Graduate School that we curtailed our marketing efforts early.

\section{Program Planning and Execution}

We aimed for a diverse and relevant program and, accordingly, the invited speakers reflected a variety of perspectives. We included UNR authors and editors from different gender and ethnic identity and subject backgrounds, including history, English, public health, environmental science, psychology, sociology, Spanish, nutrition, natural resources, geography, and Libraries. We contacted potential speakers in the mid to late fall semester, which delayed our timeline somewhat as we waited for holidays and finals to pass before receiving confirmation from several speakers. 
All sessions adhered closely to the theme of publishing, and we opted for a mix of panels and workshops (Table 1). In order to attract a wide audience, the program included concurrent sessions in both journal and book publishing. Moderators from the program planning committee oversaw each session. The moderators introduced speakers, facilitated audience participation, and kept time. While we did prepare about six to seven questions for the moderators to ask each panel, we also made sure to open up as much time as possible to questions from the audience, reserving at least half of our questions only in case there were not enough questions from the audience. Most of the events took place in the Joe Crowley Student Union, but lunch and the social hour were held next door in the campus' main library, the MathewsonIGT Knowledge Center. The split venue was due to logistics and space issues but also allowed us to help connect the event to the Libraries.

The committee designed the program to allow maximum flexibility for attendees, many of whom were graduate students who needed to come and go as their schedules allowed. We staffed a registration table in the morning and converted it to self-registration after the Welcome Session. Lunch was semi-structured, with publisher roundtables that encouraged attendees and publishers to network.

Although part of the goal for the planning committee was to promote OA, open data, and other open scholarship ideas and practices to the attendees, we also knew we had to balance this with other desires of attendees. Our institution in many ways is still to new to OA, and faculty who publish in an OA journal do not always realize this. Thus, we tried to find a balance and ways to introduce OA throughout the event, such as questions for panelists (see Table 1).

\section{Assessment}

\section{Attendance}

Registration for the event quickly reached our cap of 140 (set in anticipation that some who registered would not attend), and we kept a short waitlist for a total of 170 people. A large majority of people who registered listed themselves as graduate students (128), with just 25 saying they were faculty. The remaining people listed themselves as post-doctorates. However, the number of attendees fell short of expectations, with about $50 \%$ of those registered actually signed in on the day of the event. Although the turnout was smaller than anticipated, it was still respectable, at 75 attendees. Attendance at each individual session was mixed. The workshops and panels that addressed journal publishing were well attended, while those addressing book publishing were poorly attended, with fewer than 10 people at each one. The lunch hour, which was also advertised as an opportunity to network with publishers, drew 
the most attendees. In contrast, we anticipated that the post-conference social hour would be popular and invested more resources in catering and programming for it. Unfortunately, few people came to the social hour.

\begin{tabular}{|c|c|c|}
\hline Time & Session & Details \\
\hline 8:30 a.m. to 9:00 a.m. & Registration & - Light breakfast provided \\
\hline 9:00 a.m. to 9:55 a.m. & Welcome Session & $\begin{array}{l}\text { - Opening remarks } \\
\text { - Keynote address }\end{array}$ \\
\hline 10:00 a.m. to 11:00 a.m. & Faculty Editor Panels & $\begin{array}{l}\text { - Journal panel: How to respond to } \\
\text { peer review } \\
\text { - Book panel: What's the editor's } \\
\text { responsibility? }\end{array}$ \\
\hline 11:15 a.m. to $12: 15$ p.m. & Morning Workshops & $\begin{array}{l}\text { - Working with Coauthors } \\
\text { - Navigating the Landscape of Data } \\
\text { Sharing Policies }\end{array}$ \\
\hline 12:15 p.m. to $1: 30$ p.m. & Lunch & - $\quad$ Publisher Roundtables \\
\hline 1:30 p.m. to $2: 30$ p.m. & Publisher Panels & $\begin{array}{l}\text { - Journal panel: Choosing a journal } \\
\text { Book panel: Choosing a book } \\
\text { publisher }\end{array}$ \\
\hline 2:30 p.m. to $3: 30$ p.m. & Afternoon Workshops & $\begin{array}{l}\text { - Open Access Publishing } \\
\text { - How to Prepare a Book Proposal }\end{array}$ \\
\hline 3:45 p.m. to $4: 45$ p.m. & Early Career Authors Panel & - No concurrent session \\
\hline
\end{tabular}

Table 1. Manuscript Accepted! 2019 Program

Survey Results

In order to help assess the event, all participants were emailed a survey (see Appendix A) during the event, and 31 people responded. The survey received exempt status from the UNR Institutional Review Board.

When asked how they would rate the overall symposium, 27 people rated the event as satisfactory, while three people rated it as neutral (see Figure 1). Comments on what the participants liked best most often included the different panels, with the editors panel receiving most mentions. Comments about other topics participants would like to hear at future events were more varied. Some could be implemented, such as coming up with research ideas, writing cover letters for manuscript submissions, and a walkthrough of the journal review process. 


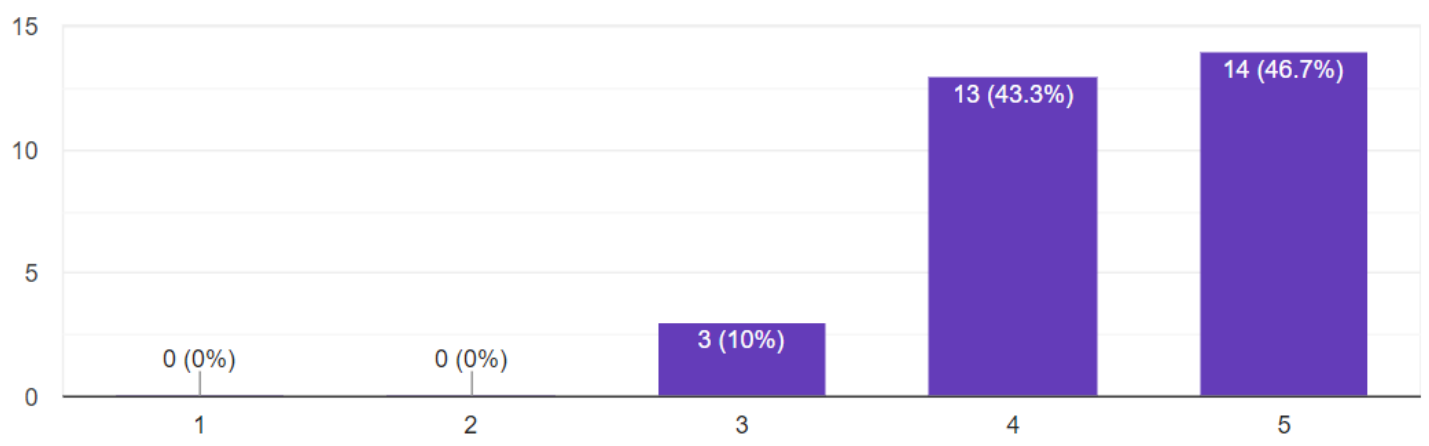

Figure 1. Number of respondents who rated the Manuscript Accepted! 2019 event a 1 (unsatisfactory) through a 5 (satisfactory).

However, we found that many of the suggestions either fell outside of the event's scope, such as how to apply for tenure, how to be a reviewer, and how to write a grant proposal. Others would not be feasible in a day-long event, such as providing more discipline-specific advice or providing a working group to review manuscripts.

Most responses regarding how the event could be improved focused on logistical issues, such as providing a coat rack and coffee all day. Several did request having more faculty from STEM fields.

\section{Second event}

Because of the success of the first Manuscript Accepted!, the Libraries decided to host a second one. Planning for the second Manuscript Accepted! event started in June 2019, with a target date of February 2020. In order to increase its adaptability, we opted to reduce the committee to four library representatives and one representative from the GSA. We met as a committee on a monthly basis.

On designing the program for the second event, one of the goals was to increase the diversity of panel members. This goal included trying to plan sessions where STEM, Social Sciences, and Humanities were represented. Also, although we tried to create diverse panels that would widely represent gender and ethnic groups for the first Manuscript Accepted!, our panels were less diverse than we had hoped, and we set about to create more inclusive panels for the 2020 event. Although work in this area started earlier, this again constituted our most challenging task, and identifying speakers took a considerable amount of time. Although we did succeed in including more women and faculty of color on each panel, we still struggled to recruit STEM faculty of any background and received several rejections or no responses. 
Another goal was to simplify the logistics in order to make it easier to attend, especially for graduate students. We opted to stick with a mid-week day in February 2020, although this time a Wednesday, but chose to consolidate all the sessions into one space, the fourth floor of the student union. At the same time, the event was shortened. Taking into account the low attendance and effort required to execute a social hour in 2019 , we opted to cut it from the 2020 program. We also removed the publishers' panel, although we continued to provide the publishers with the opportunity to interact with attendees through their own booths and with round tables during lunch. Finally, based on the low attendance for the book panels during Manuscript Accepted! 2019, we decided to have just one track for panels that included representatives experienced in book and journal editing and peerreviewing (Table 2). We did continue to offer two concurrent workshops during the two workshops session slots. Workshop topics included introductions to data sharing and OA, working with co-authors, time management on a budget, how to choose a journal for publication, and networking.

\begin{tabular}{llll} 
Time & Session & Details \\
\hline 8:30 a.m. to 9:00 a.m. & Registration & $\bullet$ & Light breakfast provided \\
\hline 9:00 a.m. to 9:55 a.m. & Welcome Session & $\bullet$ & Opening remarks \\
& & $\bullet$ & Keynote address \\
\hline 10:00 a.m. to 11:00 a.m. & Faculty Editors Panel & $\bullet$ & Role of editors and how they work \\
\hline & & $\bullet$ & Time management and self care \\
11:15 a.m. to 12:15 p.m. & Morning Workshops & $\bullet$ & $\begin{array}{l}\text { Networking with publishing stake- } \\
\text { holders }\end{array}$ \\
\hline 12:15 p.m. to 1:45 p.m. & Lunch & & Publisher roundtables \\
\hline 1:45 p.m. to 2:45 p.m. & Peer Reviewers Panel & $\bullet$ & How peer reviewers work \\
\hline 2:45 p.m. to 3:45 p.m. & Afternoon Workshops & $\bullet$ & $\begin{array}{l}\text { Choosing a journal } \\
\end{array}$ \\
& & $\bullet$ & Building an online profile
\end{tabular}

Table 2. Manuscript Accepted! 2020 Program

NEXT STEPS

Manuscript Accepted! 2020 Assessment

\section{Attendance}

A total of 156 people registered for the second event, with again 128 graduate students registering, and far fewer faculty (20). We again saw a steep decline from the number of people 
registered and those who actually checked in at the event (65). This was slightly smaller than the previous year and again fell short of our goal of 100, but we still found this to be an acceptable number for the event. The keynote was the most well-attended event, with 46 people. The other morning events saw about the same attendance, and lunch again proved popular, although students seemed reluctant to sit with the publisher representatives. Although the day ended two hours earlier than the first event, attendance after lunch dropped by about half and remained that way for the rest of the day. Attendance at the workshops, which remained as concurrent sessions, did seem more balanced than the prior year, although the panel on networking was easily the most popular with 28 people.

\section{Survey}

As we did with the first event, we emailed a survey (see Appendix B) to attendees of Manuscript Accepted! 2020, which was styled on the first survey. The only changes we made to the survey were to delete questions asking participants to rank individual sessions and to include a question asking their discipline. We added this to help us better understand what broad areas we were reaching. This survey also received exempt status from the UNR Institutional Review Board.

About half the attendees (31) responded to the survey (see Figure 1). Approximately twothirds of them came from the STEM disciplines, about a third came from the social sciences, and just three came from the humanities. We again found that almost all (29) rated the overall event as satisfactory, with one ranking it as neutral, and one ranking it as unsatisfactory.

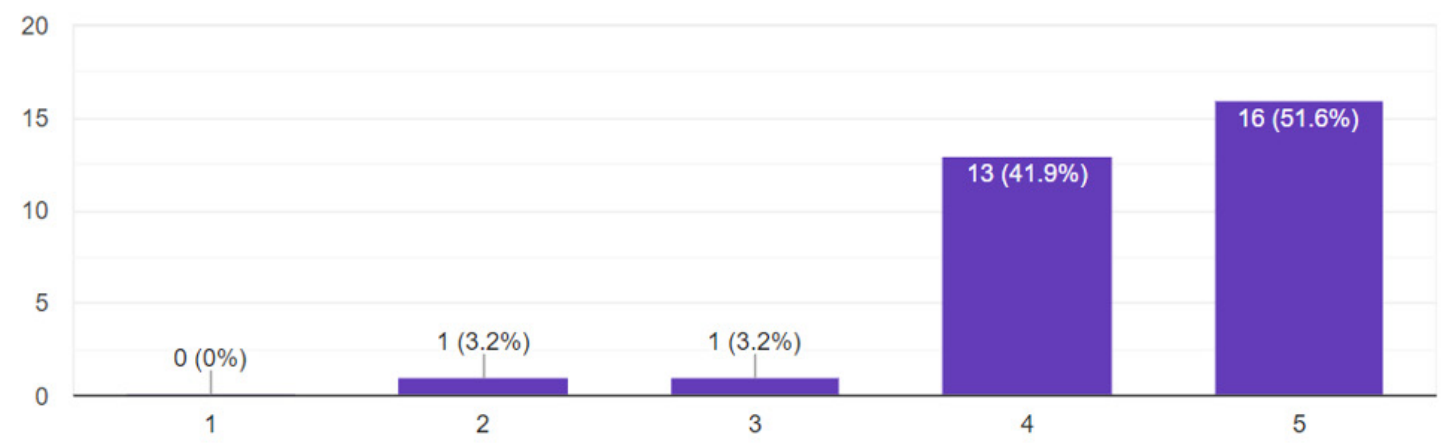

Figure 2. Number of respondents who rated the Manuscript Accepted! 2020 event a 1 (unsatisfactory) through a 5 (satisfactory). 
In looking at the open-ended comments of what attendees liked about the event, the panels featuring UNR faculty again proved the most popular. In response to what attendees would like to see in future events, organizing sessions for each of the broad disciplines, instead of grouping them all together, was again a common theme. Covering how to write was also a common suggestion, although this time there were suggestions for more basic topics that could potentially be done at future iterations, such as how to structure a manuscript. Other topics still seem to be outside the event's scope, such as grant writing, while others reflected topics that had already been addressed at either this or the first event, suggesting the students were not able to attend those sessions. Suggestions for future events included adding more descriptions about each session, focusing more on the basics of publishing, earlier advertising, and more sessions geared toward early career faculty.

\section{Possible changes for the future}

Based on the results of the first two Manuscript Accepted! events, we have continued to discuss how the event could be changed and improved in the future. One area of concern has been how often to hold the event. A full-day symposium was chosen over smaller, individual workshops partly as a way to entice students and faculty to attend, but they are also much more intensive to plan and take significant staff time, money, and other resources that can then no longer be used on other projects and services. There is also a concern of fatigue among attendees and that attendance could continue to drop if the event is held too often. Because of these concerns, we are considering moving the event to a biennial schedule.

In the future, we would also like to find a way to better connect with individuals in $\mathrm{Hu}$ manities departments. Feedback from Humanities faculty and students concerning both Manuscript Accepted! events suggested that sessions were primarily focused on STEM areas. Although our team included Humanities faculty on the panels for Manuscript Accepted! 2020 and purposely tried to include topics that would interest those in the Humanities, we still experienced low turnout from this demographic. This likely helped steer the focus of the events towards STEM and Social Sciences, as students from those disciplines dominated the question and answer periods of the panels. We are considering creating a separate, smaller event that will focus exclusively on publishing in the Humanities so that we can better serve this group.

We would also like to reach more early career faculty in future events. Although Manuscript Accepted! was marketed to both graduate students and early career faculty, few faculty members attended the second event. This might have been because the event was sponsored in part by the GSA, so potential faculty attendees might have ignored the marketing, thinking this event was not for them. It is also possible that the timing simply did not work with 
faculty schedules because both events were held in the middle of the week. And finally, faculty might not have been interested in the selected topics of the panels and workshops. In order to better serve this population, we will survey the early career faculty at the onset of the Fall 2020 semester to explore ways we can better serve their needs.

We are also considering ways to retain attendees throughout the event. With both events, attendance tended to drop off in the afternoon after lunch. Several possibilities include splitting the event over two mornings, continuing to shorten the event so it ends earlier, and moving to a later lunch so that it ends the day. We have also discussed trying other weekdays to hold the event because of concerns about class and teaching schedules. Manuscript Accepted! 2019 was held on a Tuesday, and Manuscript Accepted! 2020 was held on a Wednesday. The Libraries normally avoid Fridays for events because many students do not come to campus that day, but, with lighter schedules that day, more graduate students might attend on a Friday for a big event.

Finally, we are discussing ways to grow the event outside of the one-day symposium. This would be especially important if we do move to a biennial schedule. More small, interactive sessions would allow researchers to get help on their specific project. One of the recurring main themes in our feedback is a desire for help with how to write a manuscript or for someone to review a manuscript. Because of the differences in writing among the disciplines and the time needed to dig into such a subject, we have resisted including this in the symposium itself and will likely continue to do so. However, one possibility could be a service fair, where we invite various groups on campus, such as grant support, the writing center, and more, to come to the library for a specified time and allow students and faculty to come and receive help on their projects. We have also discussed holding writing meetups at the Libraries, where we would provide dedicated space, and the students would be in charge of leading the groups. These could also be more discipline-focused.

Overall, we found that focusing on a day-long symposium succeeded in teaching and engaging with graduate students, if not as much with early career faculty, about the scholarly publishing process. It has allowed us to collaborate with other groups on campus, which in turn we believe has made the event more successful than it would if just sponsored by the Libraries. We also took advantage of the local expertise offered by our own faculty while also incorporating librarians as speakers to help advertise the role we play. We plan on continuing to further refine Manuscript Accepted! and possibly grow it as a brand with other related events. 


\section{REFERENCES}

Association of College \& Research Libraries. (2000). Information literacy competency standards for higher education. https://alair.ala.org/bitstream/handle/11213/7668/ACRL\%20Information\%20Literacy\%20 Competency $\% 20$ Standards\%20for\%20Higher\%20Education.pdf?.sequence=18 2 isAllowed $=y$

Association of College \& Research Libraries. (2016). Framework for information literacy for higher education. http://www.ala.org/acrl/sites/ala.org.acrl/files/content/issues/infolit/framework1.pdf

Baruzzi, A., \& Calcagno, T. (2015). Academic librarians and graduate students: An exploratory study. Portal: Libraries and the Academy, 15(3), 393-407. https://doi.org/10.1353/pla.2015.0034

Belcher, W. L. (2009). Reflections on ten years of teaching writing for publication to graduate students and junior faculty. Journal of Scholarly Publishing, 40(2), 184-199. https://doi.org/10.1353/scp.0.0036

Blummer, B. (2009). Providing library instruction to graduate students: A review of the literature. Public Services Quarterly, 5(1), 15-39. https://doi.org/10.1080/15228950802507525

Bruxvoort, D., \& Fruin, C. (2014). Library support for faculty/researcher publishing. https://doi.org/10.29242 Ispec.343

Buehler, M. A., \& Zald, A. E. (2013). At the nexus of scholarly communication and information literacy: Promoting graduate student publishing success. In Common ground at the nexus of information literacy and scholarly communication (pp. 225-245). Association of College and Research Libraries, a division of the American Library Association.

Carnegie Classification of Institutions of Higher Education. (n.d.a). Basic classification. Retrieved from https://carnegieclassifications.iu.edu/classification descriptions/basic.php

Carnegie Classification of Institutions of Higher Education. (n.d.b). Graduate Instructional Program Classification. Retrieved from https://carnegieclassifications.iu.edu/classification descriptions/grad program.php

Covert-Vail, L., \& Collard, S. (2012). New roles for new times: Research library services for graduate students. https://www.arl.org/wp-content/uploads/2012/12/nrnt-grad-roles-20dec12.pdf

Critz, L., Axford, M., Baer, W. M., Doty, C., Lowe, H., \& Renfro, C. (2012). Development of the graduate library user education series. Reference Services Review, 40(4), 530-542. https://doi.org/10.1108 $\underline{100907321211277341}$

Fong, B. L. (2019). Boot camps for graduate student success: A collaborative initiative. Journal of Library Administration, 59(4), 373-394. https://doi.org/10.1080/01930826.2019.1593710

Fong, B. L., Wang, M., White, K., \& Tipton, R. (2016). Assessing and serving the workshop needs of graduate students. The Journal of Academic Librarianship, 42(5), 569-580. https://doi.org/10.1016/j.acalib .2016 .06 .003 
Grad Center at Penn. (n.d.). Navigating the academy. Retrieved from https://gsc.upenn.edu/academic -programs\#programs

Hoffman, K., Antwi-Nsiah, F., Feng, V., \& Stanley, M. (2008). Library research skills: A needs assessment for graduate student workshops. Issues in Science and Technology Librarianship, 53. https://doi.org/10.5062 /F48P5XFC

Knievel, J. E. (2008). Instruction to faculty and graduate students: A tutorial to teach publication strategies. Portal: Libraries and the Academy, 8(2), 175-186. https://doi.org/10.1353/pla.2008.0020

McClellan, S., Detmering, R., Martinez, G., \& Johnson, A. M. (2017). Raising the library's impact factor: A case study in scholarly publishing literacy for graduate students. Portal: Libraries and the Academy, 17(3), 543-568. https://doi.org/10.1353/pla.2017.0034

Nova Southeastern University Libraries. (2017, November 27). 4th annual Power Publishing Day. Spotlight. http://sherman.library.nova.edu/sites/spotlight/event/3rd-annual-power-publishing-day/

University of Nevada, Las Vegas Libraries. (n.d.). UNLV Research Week 2017. Retrieved from https://www library.unlv.edu/research week

University of Nevada, Reno Office of Institutional Analysis. (n.d.). University enrollment by semester. Retrieved from https://www.unr.edu/pba/institutional-analysis/surveys-reports/student-headcount-semester. 


\section{APPENDIX A \\ 2019 Manuscript Accepted! Participant Feedback Survey Form}

Thank you for attending Manuscript Accepted! We hope you enjoyed it. In order to learn how we can make it better, we'd appreciate it if you could fill out this short survey.

1. On a scale of 1 (unsatisfactory) to 5(satisfactory), how would you rate the entire event?
a. Likert scale options

2. On a scale of 1 (unsatisfactory) to 5 (satisfactory), how would you rate each of the following events?

a. Keynote

i. Likert scale options

b. Editors Panels

i. Likert scale options

c. Publishers Panel

i. Likert scale options

d. New Authors Panel

i. Likert scale options

e. Open Access Workshop

i. Likert scale options

f. Co-authors Workshop

i. Likert scale options

g. Data Sharing Workshop

i. Likert scale options

h. Book Proposal Workshop

i. Likert scale options

3. What did you like most overall? (open text response)

4. What other topics would you like to hear about at future events? (open text response)

5. Please let us know what could be improved or if you have any other feedback. (open text response) 


\section{APPENDIX B \\ 2020 Manuscript Accepted! Participant Feedback Survey Form}

Thank you for attending Manuscript Accepted! We hope you enjoyed it. In order to learn how we can make it better, we'd appreciate it if you could fill out this short survey.

1. What department or discipline are you in? (open text response)

2. On a scale of 1 (unsatisfactory) to 5 (satisfactory), how would you rate the entire event? a. Likert scale options

3. What did you like most overall? (open text response)

4. What other topics would you like to hear about at future events? (open text response)

5. Please let us know what could be improved or if you have any other feedback. (open text response) 